\title{
Predicting nutrient responses in poultry: future challenges
}

\author{
R. M. Gous ${ }^{\dagger}$ \\ Animal and Poultry Science, Faculty of Science and Agriculture, University of KwaZulu-Natal, P/Bag X01, Scottsville 3209, South Africa
}

Predicting the response of poultry to nutrients has progressed to a stage where it is now not only possible to predict voluntary feed intake accurately, but broiler feeds and feeding programmes may now be optimised using the more advanced simulation models. Development of such prediction models has stimulated useful and purposeful research targeted at filling the gaps in our knowledge of critical aspects of the theory incorporated into these models. The aim of this paper was to review some of these past developments, discuss the controversy that exists in designing and interpreting response experiments, and highlight some of the most recent challenges related to the prediction of responses to nutrients by poultry. These latter include differences, brought about by selection for diverse goals, that have become apparent between modern broiler strains in their responses in feed intake and mortality, which are not independent of level of feeding or strain of broiler, as was previously believed. Uniformity, an important quality criterion in broiler processing, is also not independent of level of feeding, and the effect may now be predicted using stochastic models. It is not yet clear whether breast meat yield, the carcass component of broilers yielding the highest returns, is a function of the strain of broiler or simply that of the protein weight of the bird when processed. An important aspect of response prediction is dealing with constraints to performance: whereas it is relatively straightforward to simulate the potential performance of a broiler, such performance is often constrained by the physical, social and infectious environment, among others, providing a challenge to modellers attempting to predict actual performance. Some of these constraints to potential performance have not yet been adequately described, but are now receiving attention, suggesting that nutrient responses in poultry have the potential to be more accurately predicted in the future.

Keywords: growth models, nutrition, nutrients, poultry, prediction

\section{Introduction}

Predicting responses of poultry to nutrients has been the goal of nutritionists and modellers for a long time. The controlled feeding model of a growing pig (the Edinburgh Model Pig) was the first serious and successful attempt to integrate information about an animal, its feed and the environment in which it was kept, with a view to simulating its performance (Whittemore, 1976; Whittemore and Fawcett, 1976). This provided the impetus for the development of further models, of modifications to existing models and of research targeted at filling the gaps in our knowledge of critical aspects of the theory incorporated into these models. The most important subsequent contribution to response modelling was the theory proposed by Emmans (1981) (see below) to predict voluntary feed intake in poultry and pigs, which raised the value of prediction models inestimably by making feed intake an output from, as opposed to an input to, the growth model. Models incorporating this theory are thus more realistic and useful, providing the nutritionist

\footnotetext{
${ }^{\dagger}$ E-mail: gous@ukzn.ac.za
}

with a tool for making decisions about the most appropriate course of action to take under different circumstances. Advances continue to be made, and it is now possible to optimise the feeds and feeding programmes of broilers and pigs, through the integration of a feed formulation program, a simulation model and an optimisation routine (Gous and Berhe, 2006). However, because models require a complete statement about each step in the chain of events, some interpolation must of necessity be used where appropriate data are missing (Whittemore, 1981). All models contain some such conjectures, so none can claim to be absolutely accurate. Also, as models become more sophisticated, the list of variables that may be predicted increases. Whilst progress in models and modelling has been most impressive, these limitations and opportunities provide modellers with challenges for the future, and some of these are described and discussed here.

To date, the mechanistic models that have been developed for pigs and poultry deal with the simulation of responses in a single animal or bird. Such responses are usually linear to the point where the genetic potential is reached (Fisher et al., 1973). Poultry nutritionists are 
interested in responses to nutrients in economically important outputs such as body weight (or protein) gain, breast meat yield, egg output, feed intake and conversion efficiency, numbers of chicks produced per hen, etc. Because such responses are usually measured using groups of birds, they are invariably curvilinear, being the result of integrating the responses of individuals making up that population. Populations of birds therefore cannot have 'requirements' for nutrients: what nutritionists seek are the optimum economic dietary contents of each nutrient, and for this they need to know how populations respond to increasing dietary contents of the essential nutrients. Descriptions of such responses, whilst taking account of marginal costs and revenues, are therefore invaluable in determining how to maximise or minimise the objective function chosen for any given commercial operation. Clearly, being able to predict these nutrient responses may be seen as the foundation of a successful nutritionist.

The objective of this paper is to discuss some of the issues faced by those whose interest is to predict responses in poultry. Whereas the most satisfactory simulation models are deductive in nature, they must nevertheless rely, to a greater or lesser extent, on the results of experiments to provide the numbers that will make the theory work. Yet controversy exists in the methodologies used to measure and interpret such nutrient responses, casting doubt on the accuracy of some of these numbers, the consequences of which are discussed here. It has become evident recently that some variables critically important in determining the profitability of an enterprise, such as mortality and uniformity, are not independent of level of feeding and strain of broiler, as was previously believed. Also, poultry breeding companies (Aviagen, 2006; Cobb, 2006) claim that they have been successful in improving breast meat yield, yet such improvements may be anomalies resulting from using a faster-growing, leaner bird and not because the allometric relationship between breast meat yield and body protein weight has been altered by selection. These raise important issues about correctly describing the genotypes being simulated, and whether it is possible to use a deductive approach when describing mortality and uniformity in a broiler flock. Whereas it is relatively straightforward to simulate the potential performance of a broiler, such performance is often constrained by the environment and disease, among others, providing a challenge to modellers attempting to predict actual performance. Some of these constraints to potential performance have not yet been adequately described, providing yet another challenge to those wishing to predict nutrient responses in poultry.

\section{Measuring and interpreting responses}

Before nutrient responses can be predicted it is necessary to have some measurements on which theories may be based. Indeed, one of the most important reasons for conducting experiments, apart from testing a theory or comparing two theories, is to determine the numbers that will make a theory work, such as measuring the efficiency of utilisation of the limiting amino acid for protein growth. In this section the measurement and interpretation of amino acid responses will be used as an example of the controversy that still exists in the methodologies used to measure and interpret nutrient responses. For example, the two general methods used to measure responses to individual amino acids are the graded supplementation technique (D'Mello, 1982), where a basal diet deficient in the test amino acid is progressively supplemented with increasing doses of the synthetic form of the test amino acid, and the summit dilution technique (Fisher and Morris, 1970), in which a summit feed with excessive amounts of all amino acids but with the test amino acid first-limiting is progressively diluted with either a non-protein diluent or a dilution feed with the balance of amino acids reflecting those in the summit feed. Issues have been, and are still being raised regarding these techniques, the most recent review being by D'Mello (2003). His arguments are biased in favour of the graded supplementation technique, arguing that this has been, and remains, the method most often used by nutritionists, and that the summit dilution technique 'relies on the deliberate imposition of an amino acid imbalance in the summit diet... (this being)... the precise method for the precipitation of deleterious effects in amino acid imbalance (Harper, 1964; D'Mello and Lewis, 1971; D'Mello, 1990)'. He fails to mention that the graded supplementation technique also imposes an imbalance with the same potential effects, that this imbalance is considerably greater on the most limiting feed than in the feeds in a dilution series, and that this (im)balance differs in each of the feeding treatments used with that technique. Rogers (1976) makes the point that '.. if almost any series of multifactorial experiments is examined in which a given protein is being supplemented with various amino acids to improve the quality of the protein, amino acid imbalances often become apparent'. It has been argued (Fisher and Morris, 1970; Gous and Morris, 1985) that the response may well be influenced by this change in amino acid balance.

It is salutary to note that a broiler growth model (EFG Software, 2006), based on the theory of feed intake and growth proposed by Emmans (1981), accurately predicts responses in feed intake, live weight, protein and lipid gain obtained with the summit dilution technique, but seldom does so when the graded supplementation technique has been used. Because this model takes no account of amino acid imbalances, the responses being directly related to the content of the first-limiting amino acid in the feed, the lack of agreement between observed and predicted responses when using the latter technique provides circumstantial evidence that imbalances are indeed confounding the responses to some amino acids when this technique is used. If the response to nutrients is influenced differentially by the changing amino acid balance in the test feeds, when using the graded supplementation technique, the 
coefficients of response will be lower than they should be, resulting in an overestimate of the efficiency of utilisation of the limiting nutrient. A comprehensive survey of response trials conducted using both techniques is currently underway at the University of KwaZulu-Natal with a view to identifying the characteristics of the feeds used which result in such unpredictable responses. If responses are influenced by both the level of limiting amino acid in the feed and changes in amino acid balance, then models of feed intake must be modified to take account of this confounding. The extent to which imbalances are created differs with the limiting amino acid (Rogers, 1976), so it may be necessary to model this characteristic of feed at the biochemical rather than the whole animal level.

These methodological issues would be resolved by measuring instead the response to balanced protein, thereby eliminating issues of unbalanced or imbalanced amino acid mixtures. This is the approach used by Clark et al. (1982), who used a summit dilution technique and a well-balanced protein mixture to measure the response of broilers to protein, and by Corzo et al. (2004) and Lemme et al. (2006). Kemp et al. (2005) and Berhe and Gous (2005) measured the responses of two strains of broiler to balanced protein and discovered that the strains responded quite differently to these feeds. These differences are discussed in more detail below. Unfortunately, efficiencies of utilisation of individual amino acids cannot be measured unless they are limiting in a feed, but for most other purposes it would seem prudent to measure responses to balanced, rather than unbalanced, protein mixtures.

The reasons for measuring responses are varied and include, among others, the need to determine the efficiency of utilisation of an amino acid, to define the optimum intake of an amino acid for a population and to compare responses between strains or sexes. The method of interpreting these responses would depend on the reason for their measurement, but where the objective is to define the optimum intake of a nutrient, various methods of interpretation of such responses are still used in the literature in spite of the compelling review by Morris (1989) that concludes by pointing out the value of including marginal costs and revenues in such calculations. An integration of the responses of individuals making up a population results in a curved response, the so-called Reading Model of Fisher et al. (1973), making it impossible to define a population 'requirement' for each nutrient no matter what form of equation is used to fit a curve to the data. It is always wrong to fit a broken stick model to a population response, as such a response applies only to an individual and not to a population, resulting in an underestimate of the optimum intake of the nutrient when applied to the population response.

The response to the limiting nutrient, or to balanced protein, may be of considerable interest, but not as a means of defining a 'requirement'. Where marginal costs and revenues are included in the calculation, such responses may be used to determine the optimal economic intake of the nutrient by fitting the Reading Model (Fisher et al., 1973; Morris, 1989) to the data, and this may be of some value in laying hens whose requirements are relatively stable for long periods of time. However, in the case of growing birds the 'optimal economic intake' is meaningless, as, although it may apply to the period over which the trial was conducted, the requirements and hence responses of growing birds are changing continually over time. Such responses are therefore useful for testing theories of feed intake and growth, but are of little value in defining a feeding programme for broilers.

In many instances the results of experiments have been used to define 'the requirement' for the class of poultry used in the trial. One should bear in mind that the results of any one experiment are rarely sufficiently robust that they can be universally applied in this way: strain, sex, stocking density, environmental conditions, feeding levels and programmes, among others, all interact to define the response measured, and consequently the method of interpretation used to define the 'requirement', under the sub-set of conditions applied during the experiment, is of relatively minor importance. The value of such response experiments is therefore not that they enable one to define a requirement, but rather that they can be used for more fundamental purposes, such as to measure the efficiency of utilisation of an amino acid. Because the measurement of response is central to its prediction, it is critical that each experiment is designed in such a way that the results can be used unambiguously when being incorporated into a model. Sensitivity analysis assists in identifying those aspects of a model that are particularly important, and the efficiency of utilisation of amino acids is one such aspect that needs to be accurately estimated. Are the efficiencies the same for all amino acids? Do they differ for growth and reproductive processes? Because doubt has been expressed as to the accuracy of efficiencies measured using the graded supplementation technique, resources need to be applied to resolve this important issue.

\section{Responses of interest}

Many factors need to be considered when attempting to maximise profitability in an enterprise and all of these need to be predicted if a model is to be used to determine the conditions that will yield the desired outcome. Information required for optimisation consists of feed costs at different levels of amino acid provision, a description of all the relevant animal responses, both fixed and variable costs affecting the production system, and details of revenue. The complexity of the information required would depend on the level of organisation at which the optimisation is to be made. If profit of the broiler grower is to be maximised at the farm gate, then responses in liveability, growth and feed conversion ratio will probably suffice. However, and more realistically, a wider view will be required, and the effect of broiler nutrition on 
slaughterhouse variables (eviscerated yield, rejects etc.) and further processing (breast meat, thigh and drum weight etc.) will need to be defined. Whereas such predictions have reached a high level of success, nevertheless some issues still remain unresolved and require further attention. These issues are discussed in more detail below.

\section{Feed intake}

The theory of feed intake and growth proposed by Emmans (1981 and 1989) was based on the premise that birds attempt to grow at their genetic potential, which would imply that they would attempt to eat as much of a given feed as would be necessary to grow at that rate. Factors that would prevent them from achieving this goal would be the bulkiness of the feed or the inability to lose sufficient heat to the environment in order to enable them to remain in thermal balance. This theory has been shown to predict feed intake and hence growth and carcass composition with considerable accuracy (Ferguson and Gous, 1997; Ferguson et al., 1997). Broilers (Burnham et al., 1992) and laying hens (Gous et al., 1987) have been shown to increase feed intake as the limiting nutrient in the feed is reduced, attempting thereby to obtain more of the limiting nutrient, until a dietary concentration is reached where performance is so constrained that feed intake falls. The common misconception that 'birds eat to satisfy their energy requirements' is clearly naïve and of no value in predicting voluntary feed intake.

Recently, Kemp et al. (2005) and Berhe and Gous (2005) have demonstrated that the Ross 308 strain of broiler does not apparently conform to this theory. Instead of increasing feed intake as dietary protein content is reduced, this strain reduces intake (Figure 1), resulting in a lower growth rate than in the strain (Cobb 500) whose intake conforms to Emmans' theory (1981 and 1989).

The Ross 308 strain has been selected for improved growth and feed efficiency using high protein feeds. Such selection results in leaner carcasses (Pym and Solvens, 1979) and perhaps a reduced ability to fatten when faced with feeds marginally deficient in an essential nutrient. If this were the case then such strains would be incapable of increasing feed intake on marginally deficient feeds, as a prerequisite for this is to be able to store the excess energy consumed as body lipid unless the environmental temperature were sufficiently low as to allow the birds to lose the excess energy as heat.

Where two strains are generated using the same values for the Gompertz growth parameters but with differing ratios of maximum lipid: protein in the gain, dissimilar rates of feed intake may be simulated under marginally deficient conditions (see Figure 2), but it is apparent that this parameter alone is not sufficient to simulate the widely different patterns of feed intake observed in the experiments reported above. Other differences between the strains need to be explored to explain this genotype $x$ nutrition interaction.
The decline in feed intake with dietary protein content occurs in both simulated strains in Figure 2, but at different levels of protein feeding. The feed intake theory of Emmans (1981, 1987 and 1989) does not preclude a decline in feed intake at severely deficient concentrations of the limiting nutrient: it is only on marginally deficient feeds that feed intake is predicted to increase. Where the limiting nutrient content is severely deficient, a decline in feed intake is expected to occur as a result of the severely constrained growth rates that occur on such feeds, which in turn result in a lower capacity for feed intake when measured over a fixed time period. This pattern of feed intake, over a range of feeds limiting in an amino acid, is well illustrated in Burnham et al. (1992), being typical of feed intake responses when the summit dilution technique is used to measure such responses, and which are accurately predicted using the theory of feed intake of Emmans (1981).

This general response in feed intake to decreasing contents of a limiting amino acid, namely, a linear increase followed by a decline in intake, is illustrated in Figure 3 . If one assumes that the limiting nutrient content resulting in the lowest feed intake on the right of each graph reflects an adequate supply of that nutrient, and that strains may differ in the nutrient content assumed to be adequate, then it is possible to imagine a situation in which the range of nutrient contents chosen in a response trial will result in the feed intake increasing and decreasing in the two strains respectively, as illustrated in Figure 3. Whilst this may not be the reason for the difference in their
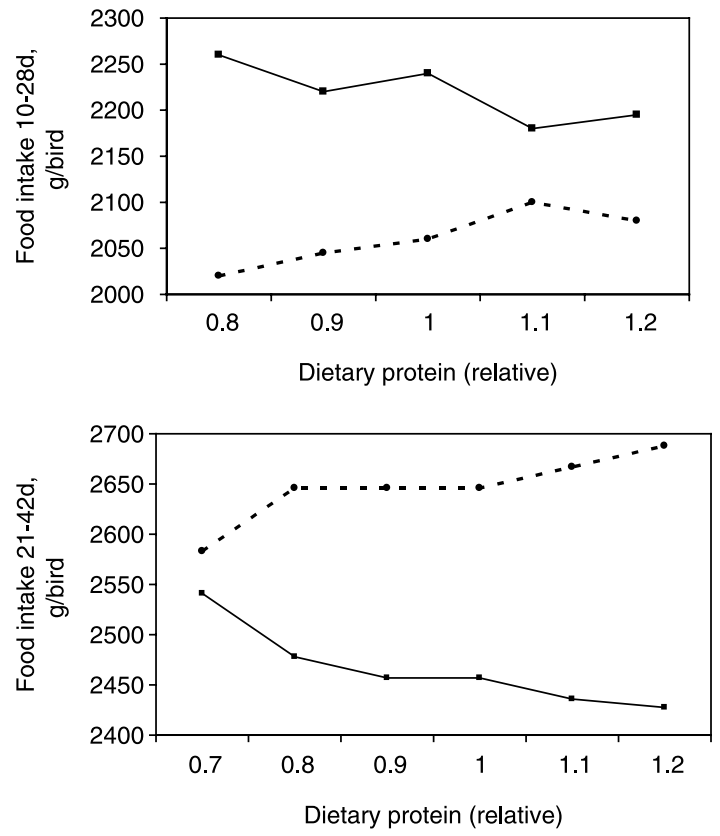

Figure 1 Response in food intake of two strains of broiler to increasing dietary balanced protein contents. Trial 1 from Kemp et al. (2005); trial 2 from Berhe and Gous (2005). Ross 308 represented by dashed line; Cobb 500 , solid line. Dietary protein contents relative to the Ross standard feeding levels (Aviagen, 2006). 


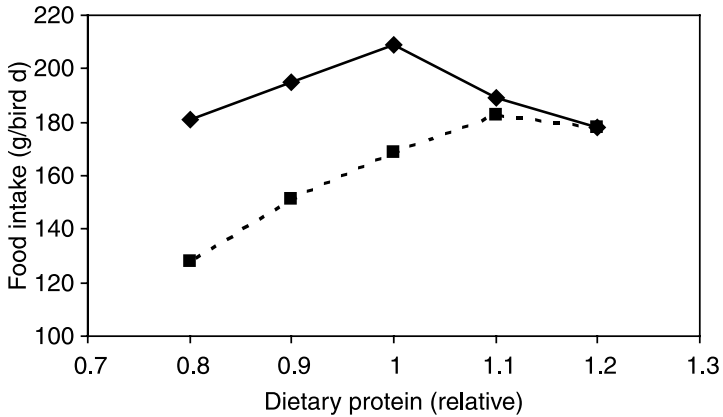

Figure 2 Simulated food intake by two hypothetical strains of broiler in the period 21 to 35 days of age, offered a range of feeds differing in balanced protein, relative to the Ross standard feeding program (Aviagen, 2006). The strains have the same values for the Gompertz growth parameters, but maximum lipid: protein ratios in the gain are 1.0 (ם) or $2.0(\diamond)$.

responses in feed intake to a limiting nutrient, it does suggest that this may not necessarily be a classical genotype $\times$ nutrient interaction. But because of the important implications of these differences when attempting to optimise the feeding of broilers, further investigations of the true cause of these differences are warranted

The environment as a constraint to achieving the desired feed intake

High temperatures are the most common reason for birds and animals not achieving their desired feed intake. It has been demonstrated (Ferguson and Gous, 1997 and 2002; Ferguson et al., 2000a and b) that as the protein or amino acid content of a feed is reduced, pigs will increase intake in an attempt to meet their requirements for potential growth, the extent to which they are able to compensate for the deficiency being dependent on the amount of heat the pig can lose to the environment, which in turn is dependent on the environmental temperature. The results of these experiments are all accurately simulated using the pig growth model (EFG Software, 2006) developed using the theory of growth of Emmans (1981, 1987 and 1989).

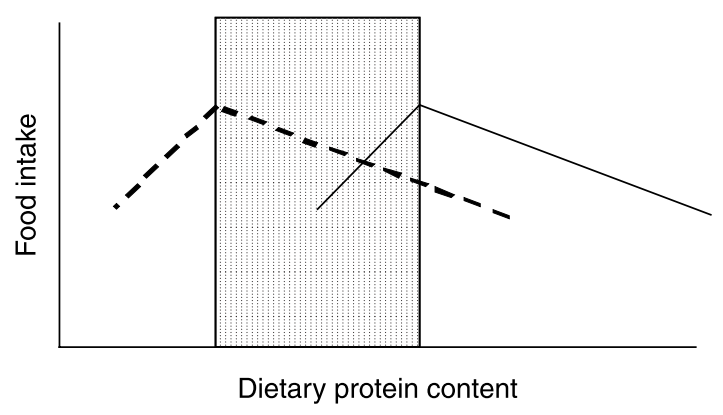

Figure 3 Simulated responses in feed intake to a range of dietary protein contents in two hypothetical broiler strains differing in the dietary protein content required to meet their potential growth. Shaded area reflects a range of dietary protein contents resulting in diametrically opposite feed intake patterns in the two strains.
Whereas birds benefit in cold weather from the insulative properties of their feather cover, this thermal barrier constrains the amount of heat that may be lost to the environment in hot weather. As the potential growth rate of broilers is increased by genetic selection, their inability to lose sufficient heat to the environment is becoming a major constraint in commercial broiler operations worldwide. Accounting for all the factors that contribute to the environmental heat demand placed on the birds, such as temperature, humidity, wind speed and thermal radiation, and then accounting for the response of the bird to this 'effective' temperature, is a major challenge when modelling the response of broilers to nutrient supply.

In very few models is feed intake an output to the model, the majority needing this variable to be input in some way or other. In such cases it is difficult to imagine that the effects of the environment on feed intake can be successfully modelled. But even where feed intake is an output, such models presently take a relatively naïve approach when describing the environment, usually describing only the environmental temperature and the relative humidity. Yet wind speed and radiation are important elements in determining the environmental heat demand on the animal, as is the fact that birds are capable of differential blood flow redistribution (McArthur, 1981) to the bare appendages of the body (wattles, comb and legs). By managing the vasoconstriction/vasodilation of the arterio-venous shunts of the skin in those anatomical regions, the bird is able to control sensible heat dissipation (Hillman et al., 1982; Hillman and Scott, 1989; Willmer et al., 2000). Accounting for these additional factors impacting on the response of the bird to its environment implies that a dynamic approach is necessary.

It is still not clear from the literature what the microenvironmental conditions are at which the bird is at least thermoregulatory effort, which would seem to be a prerequisite for predicting the environmental effects on birds when they are not in this state. Many of the experiments involving the effect of thermal stress on birds have been conducted using constant temperatures applied over long periods of time, which implies that the physiological and productive responses of the bird are in a steady-state (such as the model suggested by Mount (1979) for a homoeothermic animal), thus ignoring the important point that the environment has a dynamic, cumulative effect on chickens (Blanco and Gous, 2006). These authors have argued that responses of chickens to environmental conditions are dynamic, and depend not only on the thermoregulatory abilities of the birds and the conditions of the environmental variables to which they are exposed, but also on the time of exposure to such conditions. Birds varying in body weight will achieve thermal equilibrium with the environment following different lengths of exposure, depending on the environmental conditions as well as on their thermal properties (feather cover, comb and wattle size, acclimatisation, etc.). Blanco et al. (2004) have modelled these thermal responses, considering the 
animal characteristics as well as the environmental conditions.

It appears that there is much still to be done in explaining these thermal responses in a dynamic, time-dependent manner before being able to predict voluntary feed intake with precision.

\section{Breast meat yield}

Broilers are increasingly being further processed before being sold as parts or as boneless chicken breasts or thighs, the proportion being sold as whole birds in the USA now being less than $20 \%$ of the total production (Answers.com, 2006). Emphasis has therefore been placed by geneticists on improving breast meat yield, and highly sophisticated equipment has been developed to improve the speed and accuracy with which broiler carcasses are cut up into the required portions. Clearly, simulation models need to be able to predict the weights of the various physical parts of a broiler at different stages of growth so that this information can be used by nutritionists and economists to determine the optimum slaughter weight of broilers when they are to be sold in this way.

Whilst it is well documented that breast meat yield is related to the protein or amino acid content of the feed (Kidd et al., 2004; Lemme et al., 2006), Kemp et al. (2005) have shown that such responses are strain-dependent. They found that the response in breast meat yield continued to increase in the low feed intake strain referred to above (strain A) over the range of dietary protein contents used, whereas no further increases in yield were observed in strain B above a protein index of 110 (1.1 of the balanced amino acid recommendations of Aviagen (2006)), and the yield was significantly lower in this strain than in strain $A$. These differences are more likely to be due to differences in mature protein weight in the two strains than to differences in the allometry between breast meat yield and body protein weight, which has as yet not been shown to have been altered by selection (University of KwaZulu-Natal, unpublished). A challenge for the future is to determine whether geneticists have been successful in increasing breast meat yield at a given body protein weight, or whether the improvements that have been noted in breast meat yield in some broiler strains are not simply due to the birds being harvested at a higher protein weight or a lower fatness. Again, the differences in response between strains need to be accurately predicted if optimal feeding programmes are to be implemented.

\section{Flock uniformity}

An increasingly important characteristic of broiler production is the uniformity of body weight and conformation of birds when harvested, since consumers have become more sophisticated, demanding highly uniform whole birds and portions. There is evidence that uniformity decreases as the feed becomes marginally deficient in protein (Corzo et al., 2004) and this may be simulated using a population model such as that described by Gous and Berhe (2006) in which the performance of each individual in the population is simulated and the responses averaged. The probable cause of decreased uniformity on feeds marginally deficient in an essential nutrient is the variation in the ability of broilers to overconsume energy when faced with a deficiency. This characteristic will enable the successful birds to show little reduction in growth, whereas the feed intake of others, without the capacity to deposit as much lipid, could be severely constrained, resulting in poor growth. Furthermore, the simulation exercise suggests that at both high and low (limiting) concentrations of dietary protein uniformity increases, the requirements of all individuals in the one case being met, and in the other, all individuals being similarly constrained. So it is only on marginally deficient feeds that uniformity is compromised, a situation that is likely to occur frequently in commercial broiler operations. Thus, uniformity in a population of birds, caused by feeds varying in essential nutrient content, may be simulated mechanistically.

Variation in final body weight may be caused by many factors other than the nutrient content of the feed. Such factors would include variation in chick weight, feed uniformity, micro-climates surrounding the birds and in the ventilation system employed in the broiler house, among others (Gous and Berhe, 2006). Where differences exist in the environmental temperature at either end of a tunnel ventilated broiler house in summer, broilers fed a marginally deficient feed would perform better in the cooler end of the house because they would be capable of overconsuming more of the limiting feed than would hotter broilers. Because of such interactions between nutrient content and these non-nutritional causes of variation, it would be rewarding to make use of a population response model when predicting responses to nutrients, rather than creating an artificial population by generating a normal distribution of responses around that of the average individual in the flock. Issues related to the use of population response models are raised and discussed in Gous and Berhe (2006).

\begin{abstract}
Mortality
Mortality is not always reported in response experiments, and where it is the results are often equivocal, with little or no effect being noted in response to the limiting nutrient. However, a highly significant strain $\mathrm{x}$ feed interaction was reported by Kemp et al. (2005) indicating that strains sometimes do exhibit higher mortality when growth rate is increased through feeding a high protein feed. This has led to suggestions that growth rate should sometimes be slowed down in fast-growing strains through the use of lighting programmes (Classen, 1990), the use of mash rather than pellets (Decuypere et al., 2000), and even feed restriction (Decuypere et al., 2000). Circumstantial evidence suggests that these interventions are not necessary with all fast-growing broiler strains, implying a strain $\times$ nutrition interaction. It is difficult to see how mortality might be accounted for mechanistically in simulation models, as
\end{abstract}


these observations lack a deductive explanation, and can thus only be accounted for empirically. However, it is clear that responses will need to be strain-specific if these are to be of value when predicting performance with a view to optimising poultry feeds.

\section{Social and infectious environments}

The basis on which the amino acid requirements for growing and reproducing animals should be calculated is to start with the genetic potential of the animals and to determine what the nutrient requirements would be in order for them to achieve this potential. If no environmental factors constrain performance then this is a sensible method of determining requirements, as the potential performance will be achieved and there will be minimal wastage of valuable nutrients. However, if the animals are subjected to stresses, such as high temperatures, high stocking density, disease and low level infection, potential performance will be reduced. The question then arises whether it would be sensible to adjust the nutrient content of the feed supplied to the animals during the time of stress.

There is ample evidence that the potential performance of animals is reduced when under stress. Examples abound of poorer growth rates at high temperatures, at high stocking densities and when the animals are suffering from an infection. However, little evidence exists of how the animals should be fed under such circumstances. The solution to this dilemma may be approached in two ways: the first is that, because the feed intake of the animals will be reduced as a result of the stress, the concentration of nutrients in the feed should be kept the same or even increased under such situations. The second theory proposes that because the potential of the animals will be compromised by the stress there is no reason to supply food with the same nutrient content as would be supplied if they were growing at their potential. Stressors such as stocking density and group size do not appear to reduce the efficiency of utilisation of amino acids in pigs (University of KwaZuluNatal, unpublished) or broilers (C. Fisher and R.M. Gous, unpublished), but simply reduce feed intake. These effects may therefore be successfully simulated by reducing the rate of maturing parameter $(B)$ in the Gompertz growth equation, which results in the down-regulation of lean tissue growth (Wellock et al., 2006). In a simulation of these effects (C. Fisher and R.M. Gous, unpublished), the optimum feed composition was shown to be no different for broilers kept at high stocking densities as for those allowed ample space to grow. But where a slower-growing genotype was used, the optimum composition of feeds differed markedly from that for a fast-growing genotype, yet it was no different for the stocking densities used in the simulation. Therefore the optimum nutrient composition in feeds for broilers kept at high stocking densities, or under other conditions of stress that reduce feed intake, does not relate to the apparent reduced potential of the bird, as shown by the difference in optimum feed composition when a slow-growing genotype is used; instead, because the efficiency of utilisation of dietary nutrients is not altered, the optimum dietary composition remains the same. However, not all stressors reduce feed intake alone: certain diseases, such as those associated with the digestive and absorptive processes, may cause a reduction in utilisation efficiency and this would be worth exploring further.

A novel approach was used by Sandberg et al. (2006) for predicting the effects of sub-clinical pathogen challenges of different doses and virulence on the relative feed intake of animals. This more sophisticated approach to the problem of predicting the effects of an infection on performance models the rate of reduction in feed intake as a disease challenge progresses through the animal, enabling actual feed intake to be predicted from the relative feed intake and animal state. The deductive approach used by Sandberg et al. (2006) models differences in the degree of infection, the effect of prior exposure to the organism, and the range over which the population becomes infected, thereby producing a more realistic response to an infection than is obtained by simply reducing the rate of maturing parameter. The pattern of relative feed intake during the course of an infection would clearly differ also with the type of infection (viral, bacterial, etc.) and with the tissues or organs targeted. There is scope to take this approach further, and Sandberg et al. (2007) have led the way by identifying the key problems that would need to be solved for predicting the performance of animals exposed to pathogens.

\section{Discussion}

It has been 30 years since the Edinburgh Model Pig entered the scientific arena and since then the progress that has been made in predicting performance of broilers and pigs has been enormous. The Edinburgh Broiler Model (Emmans, 1987) was an improvement on the Pig Model, mainly because it predicted voluntary feed intake as opposed to using a controlled feeding approach. The theory used to predict feed intake (Emmans, 1981) has had major advantages for modellers, as it has been successfully applied in simulating the effect of, among others, changes in dietary amino acid and protein content, environmental temperature, infection and social stress. It has led to feed intake being an output from models instead of being an input, which has enabled models to be used to optimise feeds and feeding programmes, a process not possible unless feed intake is accurately predicted. It has spawned many useful scientific studies that have corroborated the theory, and it has led to a simplified method of accounting for the heat produced by an animal when consuming a given feed, known as the effective energy system (Emmans, 1994). And because the effective (or net) energy value of a feed is a function of both the feed and the animal being fed, what would be the advantage of describing 
feeds in these terms if a model were not available to determine the value of this feed to the animal itself? Those early models stimulated useful and purposeful research targeted at filling the gaps in our knowledge of critical aspects of the theory incorporated into these models, this being useful in itself in improving the scientific value of research.

In spite of the progress made in the past decades, there are still many challenges that lie ahead for those wishing to predict responses to nutrients in poultry. Many of these have been raised through the development of existing models. For example, the need to understand how to describe the environment and the way it impacts on broiler performance has greater meaning when this information can be linked to a prediction of the constraining effect of high temperatures on voluntary feed intake. It has been demonstrated that significant changes have taken place in broiler genotypes over time, and that the genotypes available today differ substantially in their composition and in the way they deal with marginally deficient feeds, yet updating the description of these genotypes would be of little value if this information could not in some way be used to simulate the performance of these birds under varied feeding and environmental conditions, from which optimum feeds and feeding programmes could be predicted. Also, it only really matters whether the efficiency of utilisation of an amino acid by a broiler for growth is 0.75 or 0.80 if this is to be used to predict the requirement by the broiler for that amino acid: this information is of no value if the requirement for the amino acid is being derived purely from the results of a growth trial.

Apart from the problems described above, there are others that still need to be resolved to provide nutritionists with the tools to make informed decisions about poultry feeding. The voluntary feed intake of laying hens, for example, has not yet been modelled mechanistically, with nutritionists still relying on empirical equations based on energy requirements such as those of Emmans (1974) as the basis for such prediction. Yet the principles are the same as those for predicting feed intake in broilers, the main difference being in the definition of potential performance. But a model has now been developed that adequately describes the ovulatory cycle of a laying hen, from which laying performance and egg composition throughout the laying cycle may be modelled (Johnston and Gous, 2006). What remains is to model the effect of inadequate nutrient intake on egg production. Similarly, the performance of broiler breeder hens, in response to daily nutrient allocations, needs to be adequately modelled. There remain opportunities for simulation modellers to address these and other challenges in the future.

Sadly, the world does not seem to be as enthusiastic about models as are the modellers themselves. This is partially the result of scepticism brought about through bad experiences with (bad) models. Many sets of empirical equations have been termed 'models', some of which are robust and useful, such as the model to predict age at first egg of laying pullets for any specified pattern of photoperiod used during the rearing period (Lewis et al., 2003), whilst many others are simply equations representing the result of a single experiment, with little or no predictive value outside of the experiment itself. It is the latter that have justifiably caused this scepticism. One of the challenges faced by those predicting responses to nutrients is to convince the poultry industry that good models have the potential to be of immense benefit to nutritionists, geneticists and other decision-makers in the industry. Whilst the exercise of modelling is intellectually stimulating, the practical implementation of these models in the industry is immensely satisfying.

\section{References}

Answers.com 2006. Poultry slaughtering and processing. Retrieved November 2006 from http:///answers.com/topic/poultry-slaughtering-and-processing

Aviagen 2006. Ross broiler management manual. Aviagen Ltd, Newbridge, UK.

Berhe ET and Gous RM 2005. Effect of dietary protein content on allometric relationships between carcass portions and body protein in Cobb and Ross broilers. Proceedings of the 24th conference of South African branch of WPSA, Pretoria

Blanco OA and Gous RM 2006. Considerations for representing micro-environmental conditions in simulation models for broiler chickens. In Mechanistic modelling in pig and poultry production (eds. RM Gous, TR Morris and C Fisher), pp. 188-208. CABI, Wallingford, UK.

Blanco OA, Gous RM and Savage MJ 2004. A simulation model for estimating the effect of warm micro-environmental conditions on the heat balance of a broiler. In Proceedings of the XII World Poultry Congress, Istanbul, Turkey. CD-rom.

Burnham D, Emmans GC and Gous RM 1992. Isoleucine responses in broiler chickens. Interactions with leucine and valine. British Poultry Science 33, 71-87.

Clark FA, Gous RM and Morris TR 1982. Response of broilers to well-balanced protein mixtures. British Poultry Science 23, 433-446.

Classen HL 1990. Effects of increasing photoperiod length on broiler productivity and health. Proceedings of the Australian Poultry Science symposium, pp. 55-61

Cobb 2006. Cobb 500 management manual. Retrieved November 2006 from http///cobb-vantress.com

Corzo A, McDaniel CD, Kidd MT, Miller ER, Boren BB and Puncher BI 2004. Impact of dietary amino acid concentration on growth, carcass yield, and uniformity of broilers. Australian Journal of Agricultural Research 55, 1133-1138.

Decuypere E, Buyse J and Buyse N 2000. Ascites in broiler chickens: exogenous and endogenous structural and functional causal factors. World's Poultry Science Journal 56, 367-377.

D'Mello JPF 1982. A comparison of two empirical methods of determining amino acid requirements. World's Poultry Science Journal 38, 114-119.

D'Mello JPF 1990. Lysine utilisation by broiler chicks. Proceedings of VIII European Poultry Conference, Barcelona, Spain, pp. 302-305.

D'Mello JPF 2003. Responses of growing poultry to amino acids. In Amino acids in animal nutrition second edition (ed. JPF D'Mello), pp. 237-263. CABI Publishing, Wallingford, UK.

D'Mello JPF and Lewis D 1971. Amino acid interactions in chick nutrition. 4. Growth, food intake and plasma amino acid patterns. British Poultry Science 12, 345-358.

EFG Software 2006. Broiler growth model (version 6), Broiler nutrition optimiser (version 1), Pig growth model (version 2) and Pig nutrition optimiser (version 1). Retrieved August 2006 from www.efgsoftware.com

Emmans GC 1981. A model of the growth and feed intake of ad libitum fed animals, particularly poultry. In Computers in animal production (eds. GM Hillyer, CT Whittemore and RG Gunn), British Society of Animal Production occasional publication no. 5. pp. 103-110. BSAP, Edinburgh.

Emmans GC 1994. Effective energy - a concept of energy utilisation applied across species. British Journal of Nutrition 71, 801-821. 
Emmans GC 1987. Growth, body composition and feed intake. World's Poultry Science Journal 43, 208-227.

Emmans GC 1974. The effects of temperature on the performance of laying hens. In Energy requirements of poultry (eds. TR Morris and BM Freeman), pp. 79-90. British Poultry Science Ltd, Edinburgh.

Emmans GC 1989. The growth of turkeys. In Recent advances in turkey science (eds C Nixey and TC Grey), pp. 135-166. Butterworths, London.

Ferguson NS, Arnold GA, Lavers G and Gous RM 2000a. The response of growing pigs to amino acids as influenced by environmental temperature. 1. Threonine. Animal Science 70, 287-297.

Ferguson NS, Arnold GA, Lavers G and Gous RM 2000b. The response of growing pigs to amino acids as influenced by environmental temperature. 2 . Lysine. Animal Science 70, 299-306.

Ferguson NS and Gous RM 1997. The influence of heat production on voluntary food intake in growing pigs given protein-deficient diets. Animal Science 64, 365-378.

Ferguson NS and Gous RM 2002. The response of growing pigs to amino acids as influenced by environmental temperature: tryptophan. Animal Science 74, 103-110.

Ferguson NS, Gous RM and Emmans GC 1997. Predicting the effects of animal variation on growth and food intake in growing pigs using simulation modelling. Animal Science 64, 513-522.

Fisher C and Morris TR 1970. The determination of the methionine requirement of laying pullets by a diet dilution technique. British Poultry Science 11, 67-82.

Fisher C, Morris TR and Jennings RJ 1973. A model for the description and prediction of the response of laying hens to amino acid intake. British Poultry Science 14, 469-484.

Gous RM and Berhe ET 2006. Modelling populations for purposes of optimisation. In Mechanistic modelling in pig and poultry production (eds. RM Gous, TR Morris and C Fisher), pp. 76-96. CABI, Wallingford, UK.

Gous RM, Griessel M and Morris TR 1987. Effect of dietary energy concentration on the response of laying hens to amino acids. British Poultry Science 28, 427-436.

Gous RM and Morris TR 1985. Evaluation of a diet dilution technique for measuring the response of broiler chickens to increasing concentrations of lysine. British Poultry Science 26, 147-161.

Harper AE 1964. Amino acid toxicities and imbalances. In Mammalian protein metabolism vol. II, (eds. HN Munro and JB Allison), pp. 87-134. Academic Press, New York.

Hillman P and Scott NR 1989. Energy budget of the chicken foot. Journal of Thermal Biology 14, 205-217.

Hillman P, Scott NR and Van Tienhoven A 1982. Vasomotion in chicken foot: a dual innervation of arteriovenous anastomoses. American Journal of Physiology 242, R582-R590.

Johnston SA and Gous RM 2006. Modelling egg production in laying hens. In Mechanistic modelling in pig and poultry production (eds. RM Gous, TR Morris and C Fisher), pp. 229-259. CABI, Wallingford, UK.

Kemp C, Fisher C and Kenny M 2005. Genotype - nutrition interactions in broilers; response to balanced protein in two commercial strains. Proceedings of the 15th European symposium on poultry nutrition, Balatonfüred, Hungary, pp. 54-56.

Kidd MT, Corzo A, Hoehler D, Kerr BJ, Barber SJ and Branton SL 2004. Threonine needs of broiler chickens with different growth rates. Poultry Science 83 , 1368-1375.

Lemme A, Wijtten PJ, Van Wichen J, Petri A and Langhout DJ 2006. Responses of male growing broilers to increasing levels of balanced protein offered as coarse mash or pellets of varying quality. Poultry Science $85,721-730$.

Lewis PD, Morris TR and Perry GC 2003. Effect of two opposing changes in photoperiod upon age at first egg in layer-hybrid pullets. Journal of Agricultural Science, Cambridge 140, 373-379.

McArthur AJ 1981. Thermal insulation and heat loss from animals. In Environmental aspects of housing for animal production (ed. JA Clark), pp. 37-60. Butterworths, London.

Morris TR 1989. The interpretation of response data from animal feeding trials. In Recent developments in poultry nutrition (eds. DJA Cole and W Haresign), pp. 1-11. Butterworths, London.

Mount LE 1979. Adaptation to thermal environment: man and his productive animals. Edward Arnold, London.

Pym RAE and Solvyns AJ 1979. Selection for food conversion in broilers: body composition of birds selected for increased body-weight gain, food consumption and food conversion ratio. British Poultry Science 20, 87-97.

Rogers QR 1976. The nutritional and metabolic effects of amino acid imbalances. In Protein metabolism and nutrition (eds. DJA Cole, KN Boorman, PJ Buttery, D Lewis, RJ Neale and H Swan), pp. 279-301. Butterworths, London.

Sandberg F, Emmans GC and Kyriazakis I 2006. A model for predicting food intake of growing animals during exposure to pathogens. Journal of Animal Science 84, 1552-1566.

Sandberg F, Emmans GC and Kyriazakis I 2007. The effects of pathogen challenges on the performance of naïve and immune animals: the problem of prediction. Animal 1, 67-86.

Wellock IJ, Emmans GC and Kyriazakis I 2006. The effects of social stressors on the performance of growing pigs. In Mechanistic modelling in pig and poultry production (eds. Gous RM, TR Morris and C Fisher), pp. 54-75. CABI, Wallingford, UK.

Whittemore CT 1976. A study of growth responses to nutrient inputs by modelling. Proceedings of the Nutrition Society 35, 383-391.

Whittemore CT 1981. Animal production response prediction. In Computers in animal production (eds. GM Hillyer CT Whittemore and RG Gunn), British Society of Animal Production occasional publication no. 5. pp. 47-64. BSAP, Edinburgh.

Whittemore CT and Fawcett $R$ 1976. Theoretical aspects of a flexible model to simulate protein and lipid growth in pigs. Animal Production 22, 87-96.

Willmer P, Stone G and Johnston L 2000. Environmental physiology of animals. Blackwell Science, Oxford. 